\title{
EFFICACY OF DEXAMETHASONE AS AN ADJUVANT TO BUPIVACAINE IN SUPRACLAVICULAR BRACHIAL PLEXUS BLOCK
}

Rakesh Nigam¹, M. Murthy², D. Kosam³ , A. R. Kujur ${ }^{4}$

\section{HOW TO CITE THIS ARTICLE:}

Rakesh Nigam, M. Murthy, D. Kosam, A. R. Kujur. "Efficacy Of Dexamethasone As An Adjuvant To Bupivacaine In Supraclavicular Brachial Plexus Block". Journal of Evolution of Medical and Dental Sciences 2015;

Vol. 4, Issue 64, August 10; Page: 11157-11163, DOI: 10.14260/jemds/2015/1607

\begin{abstract}
AIMS: Brachial plexus nerve blocks have analgesic and opioid sparing benefits for upper extremity surgery. Single-injection techniques are limited by duration of local anaesthetic agents, however Continuous block techniques can be used for prolonged anaesthesia and analgesia but it presents management challenges. The study was designed to compare the effects of dexamethasone administered as an adjunct to bupivacaine in supraclavicular brachial plexus block on the onset,duration and postoperative analgesia following upper limb surgeries. METHODS AND MATERIAL: A prospective, double-blind study was undertaken in patients scheduled for upper limb surgeries under supraclavicular brachial plexus block. Sixty patients were randomly divided into two groups, Group B and BD.Group B received $30 \mathrm{ml}$ of $0.375 \%$ bupivacaine with $2 \mathrm{ml}$ normal saline while Group BD received $30 \mathrm{ml}$ of $0.375 \%$ bupivacain with $2 \mathrm{ml}(8 \mathrm{mg})$ dexamethasone for supraclavicular brachial plexus block. The groups were compared regarding quality of sensory and motor blockade, duration of post operative analgesia and intra and postoperative complications. RESULTS: There was a significant increase in duration of motor and sensory block and analgesia in Group BD as compared to Group B patients $(\mathrm{P}<0.0001)$. No significant side effects were noted. CONCLUSIONS: The addition of $8 \mathrm{mg}$ of dexamethasone to bupivacaine in supraclavicular brachial plexus block prolongs the duration of motor and sensory block and extends the analgesia period.
\end{abstract}

KEYWORDS: Anaesthesia adjuvants; Dexamethasone; Brachial plexus block.

INTRODUCTION: Brachial plexus block is a suitable alternative to general anesthesia for elbow, forearm and hand surgery.(1) Local anaesthetics alone does not provide analgesia for more than 4-8 hours Prolonging the duration of sensory and motor blockade of regional anaesthetic techniques is often desirable to provide intra operative anesthesia and analgesia in the post operative period without any systemic side effects. Several adjuncts have been studied to potentiate efficacy of brachial plexus block including opioids, midazolam, neostigmine, bicarbonate,hyaluronidase and $\alpha 2$ agonists.(2,3,4) Perineural injection of steroids is reported to influence post operative analgesia.They relieve pain by reducing inflammation and blocking transmission of nociceptive C-fibres and by suppressing ectopic neural discharge. Some studies have demonstrated the analgesic effect of local spinal and systemic corticosteroids in combination with bupivacaine. $(5,6,7)$ The study was designed to compare the effects of dexamethasone administered as an adjunct to bupivacaine in supraclavicular brachial plexus block on the onset,duration and postoperative analgesia following upper limb surgeries.

MATERIAL AND METHODS: After approval by Institutional Ethical Committee, this study was carried out on 60 American Society of Anesthesiologists(ASA) I/II patients of either sex, in the age group of 20-60 years having fractures of forearm bones for open reduction and internal fixation 
under supraclavicular brachial plexus block. Exclusion criteria were refusal to regional anesthesia, infection at site, history of allergic reaction to study drugs, systemic use of corticosteroid for 2 weeks or longer, drug abuse, peripheral neuropathy, head injury, respiratory or cardiac diseases, pregnancy,having bleeding disorders, peptic ulcer disease and failure to achieve adequate block within 30 min of administration. Patients were divided into two groups of 30 patients each.Patients were assigned to receive either of the following drugs mixtures:.Group B received $30 \mathrm{ml}$ of $0.375 \%$ bupivacain with $2 \mathrm{ml}$ normal saline while Group BD received $30 \mathrm{ml}$ of $0.375 \%$ bupivacaine with $2 \mathrm{ml}(8 \mathrm{mg})$ dexamethasone for supraclavicular brachial plexus block.

Randomization was achieved by computer generated random number table. After shifting the patient inside operation theatre, drug solution for infusion was prepared by anesthesiologist not involved in the study according to randomization. The observer who collected the intra-operative data was blinded to the drug solution administered.

All patients were kept nil orally for at least $6 \mathrm{~h}$ before the procedure. Premedication was given in the form of tablet alprazolam $0.5 \mathrm{mg}$ and tablet ranitidine $150 \mathrm{mg}$ at $10 \mathrm{pm}$ night before surgery. On arrival in the operating room, intravenous line was set using 18 gauge cannula and an infusion of Ringer's lactate was started. The patients were monitored for heart rate (HR), noninvasive measurements of systolic blood pressure(SBP), diastolic blood pressure (DBP), mean arterial blood pressure (MAP) at an interval of 5 min, continuous electrocardiographic (ECG) monitoring, and hemoglobin oxygen saturation (SPO2) throughout the perioperative period. After appropriate patient positioning and strict aseptic and antiseptic precautions midclavicular point, external jugular vein and subclavian artery pulsation were identified. About $2 \mathrm{~cm}$ above the midclavicular point just lateral to subclavian artery pulsation, a 24gauge and 1.5inch long needle was introduced and directed caudal and medially until paraesthesia was encountered, when $32 \mathrm{ml}$ of local anaesthetics with or without dexamethasone was injected at the site. A 5 min compression at the injection site was performed to facilitate an even drug distribution.

Routine monitoring of all the patients including blood pressure, pulse rate, Sp02, electrocardiogram was done. We evaluated onset, quality and duration of sensory and motor block along with side effects if any.

For sensory loss assessment, we used pin prick test with a three-point scale-0- Sharp pain felt, 1- Analgesia(dull sensation felt), 2- Anesthesia(no sensation felt).(8)

Motor block was assessed by modified Bromage scale for upper extremities, using a 3 point scale. 0total movement of fingers and wrist, 1-decreased motor strength with ability to move the fingers only, 2-inability to move fingers. (9)

Block was evaluated every 3 min till complete motor and sensory block after the injection of local anesthetic. Further block assessment was done at hourly intervals up to $24 \mathrm{hr}$ by a blinded anesthesiologist.

Onset of sensory blockade was defined as the interval between the end of injection and loss of sensation to pinprick or by score 1 of pinprick response.

Onset of motor blockade was the interval between the end of injection and complete motor paralysis of wrist and hand.

The duration of sensory blockade being the time interval between sensory blockade and reappearance of pinprick response.

The duration of motor blockade was defined as the time interval between maximum motor blockade and complete movement of wrist and fingers. 


\section{ORIGINAL ARTICLE}

Duration of analgesia was taken as the time interval between onset of sensory blockade and the first dose of rescue analgesic given to the patient (VRS $>4$ ).

Pain assessment in the postoperative period was done using verbal response score, being obtained by asking the patient to rate the intensity of pain perceived by him/her and express it on a numerical scale of 0 to 10 , with 0 -no pain(One extreme). 10-worst pain possible (other extreme). Rescue analgesia in the form of injection diclofenac $75 \mathrm{mg}$ intramuscularly was given to patients with VRS $>4$. All the patients were monitored intra-operatively and postoperatively in terms of hemodynamic stability and for any side effects.

STATISTICAL ANALYSIS: Categorical variables like ASA status, sex, postoperative analgesic requirement and adverse effects have been compared between groups by using Chi square test. Normally distributed numerical variables were analyzed using unpaired " $t$ " test. Skewed numerical variables within the group were analyzed using Man-Whitney " $U$ " test. All tests were two tailed. Significance was defined as $\mathrm{P}<0.05$.

RESULTS: Total number of patients participated in the study were 34 in group B and 35 in group BD. The number of patients who had partial blocks or failed blocks was 4 in Group B and 5 in Group BD. After excluding these patients, the total number of patients taken for study was 30 in each group. The demographic profiles in both the groups were comparable with respect to age, gender, weight and duration of surgery.[Table 1]

\begin{tabular}{|c|c|c|c|}
\hline & Group B & Group BD & P Value \\
\hline Age (Yrs.) & $41.27 \pm 5.64$ & $40.4 \pm 4.74$ & 0.52 \\
\hline Sex(M/F) & $18: 12$ & $22: 08$ & 0.273 \\
\hline Wt. mean & $54.13 \pm 7.24$ & $52.83 \pm 6.8$ & 0.476 \\
\hline Mean Duration of Surgery & $80.75 \pm 10.49$ & $81.88 \pm 11.12$ & $>0.05$ \\
\hline
\end{tabular}

The mean time of onset of sensory block in Group B was 13.93 \pm 1.66 min and in group Group $\mathrm{BD}$ was $12.90 \pm 1.49 \min (\mathrm{P}=0.196)$ [Table 2$]$.

\begin{tabular}{|c|c|c|c|}
\hline & Group B & Group BD & P Value \\
\hline Onset of sensory block (Min) & $13.93 \pm 1.66$ & $12.90 \pm 1.49$ & 0.196 \\
\hline Onset of moter block (Min) & $18.47 \pm 2.0$ & $16.76 \pm 2.34$ & 0.004 \\
\hline Duration of moter block & $202.93 \pm 30.55$ & $393.03 \pm 98.96$ & $<.001$ \\
\hline Duration of sensory block & $453.17 \pm 72.81$ & $1028.17 \pm 194.51$ & $<.001$ \\
\hline Time to first rescue analgesic & $605.37 \pm 58.60$ & $1278.8 \pm 82.83$ & $<.001$ \\
\hline \multicolumn{4}{|r}{ Table 2: summary of results }
\end{tabular}

The mean duration of sensory block was statistically significant in both the group,it was 453.17 \pm 72.18 min in Group B and was $1028.17 \pm 194.15 \mathrm{~min}$ in Group BD ( $\mathrm{P}=0.001)$ [Table 2]. The mean time of onset of motor block in Group B was $18.47 \pm 2.0$ min while mean time of onset of motor block in Group BD was 16.76 \pm 2.34 min was also statistically significant $(\mathrm{P}=0.004)$ [Table 2]. The mean duration of motor block was longer in BD group $(393.03 \pm 98.96 \mathrm{~min})$ as compared to 


\section{ORIGINAL ARTICLE}

$202.93 \pm 30.55 \mathrm{~min}$ in Group B. $(\mathrm{P}<0.001)$ [Table 2]. The mean time to the demand of first rescue analgesic in the form of injection diclofenac was significantely higher in group BD (1278.8 \pm 82.83$)$ as compared togroup B(605.37 \pm 58.60$)[\mathrm{P}<0.001]$.

Complication in the form of nausea and vomiting was observed in one patient in group $\mathrm{B}$ and two patient in group BD which were statistically insignificant.There were no incidences of adverse effects like sedation, hypotension, and pneumothorax in any group [Table 3].

\begin{tabular}{|c|c|c|c|}
\hline & Group B & Group BD & P Value \\
\hline Sedation & 0 & 0 & - \\
\hline Nausea & 1 & 2 & 1 \\
\hline Vomiting & 0 & 0 & - \\
\hline Hypotension & - & 0 & - \\
\hline Pneumothorax & 0 & 0 & - \\
\hline \multicolumn{4}{|c|}{ Table 3: Side effect in two group } \\
\hline
\end{tabular}

DISCUSSION: Our study demonstrates that the combination of dexamethasone and bupivacaine used for supraclavicular brachial plexus block hastens the onset of motor block and provides a longer duration of sensory and motor blockade and postoperative analgesia as compared to plain bupivacaine(control group).

Movafegh A found that the addition of dexamethasone to lidocaine $1.5 \%$ solution in axillary brachial plexus block prolongs the duration of sensory and motor blockade.(10) Prashant et al in their study also found that Addition of dexamethasone to $1.5 \%$ lidocaine with adrenaline in supraclavicular brachial plexus block speeds the onset and prolongs the duration of sensory and motor blockade.(11)

Santosh Kumar et al.demonstrated that the addition of $8 \mathrm{mg}$ of dexamethasone to $0.5 \%$ ropivacaine for supraclavicular brachial plexus prolongs sensory and motor block as compared ropivacaine given alone.(12) Their findings were same as that of our study, but there was no significant difference in the onset of motor block among both groups in their study. This finding of hastening the onset motor block in dexamethasone group may be due to different pharmacodynamic properties of ropivacaine than bupivacaine, which was used in our study.

Shaikh et al. evaluated the use dexamethasone $8 \mathrm{mg}$ as an adjuvant to bupivacaine $0.25 \%$, total volume being $40 \mathrm{ml}$, in supraclavicular brachial plexus block given for various upper limb surgeries and concluded that addition of $8 \mathrm{mg}$ dexamethasone to bupivacaine $0.25 \%$ solution in supraclavicular brachial plexus block prolongs the duration of sensory and motor blockade, reduces the requirement of rescue analgesic in postoperative period but has no effect on the onset time of sensory and motor block.[13]

Kaabachi et al. reported Using ultrasound-guided single-shot supraclavicular blockade with low-dose dexamethasone in a mixture with levobupivacaine results in prolonged analgesia duration and less analgesic use compared with levobupivacaine alone in patient of upper extremity surgery.[14]

Parrington et al. observed that that the addition of dexamethasone to mepivacaine for ultrasound-guided supraclavicular brachial plexus block in patients undergoing upper-limb surgery provides a longer duration of postoperative analgesia when compared to brachial block performed with $0.5 \%$ levobupivacaine alone.[15] 


\section{ORIGINAL ARTICLE}

In our study, only one patient in control group and two patient in study group had nausea and vomiting were managed symptomatically.

We were unable to use ultrasound or nerve stimulator guided blocks due to its unavailability in our institution at the time of our study which could have helped us to lower volume of local anesthetic and less failed block. To conclude $8 \mathrm{mg}$ of dexamethasone when added to bupivacine $0.375 \%$ in supraclavicular brachial plexus block prolongs the duration of motor and sensory block and extend the analgesia period.

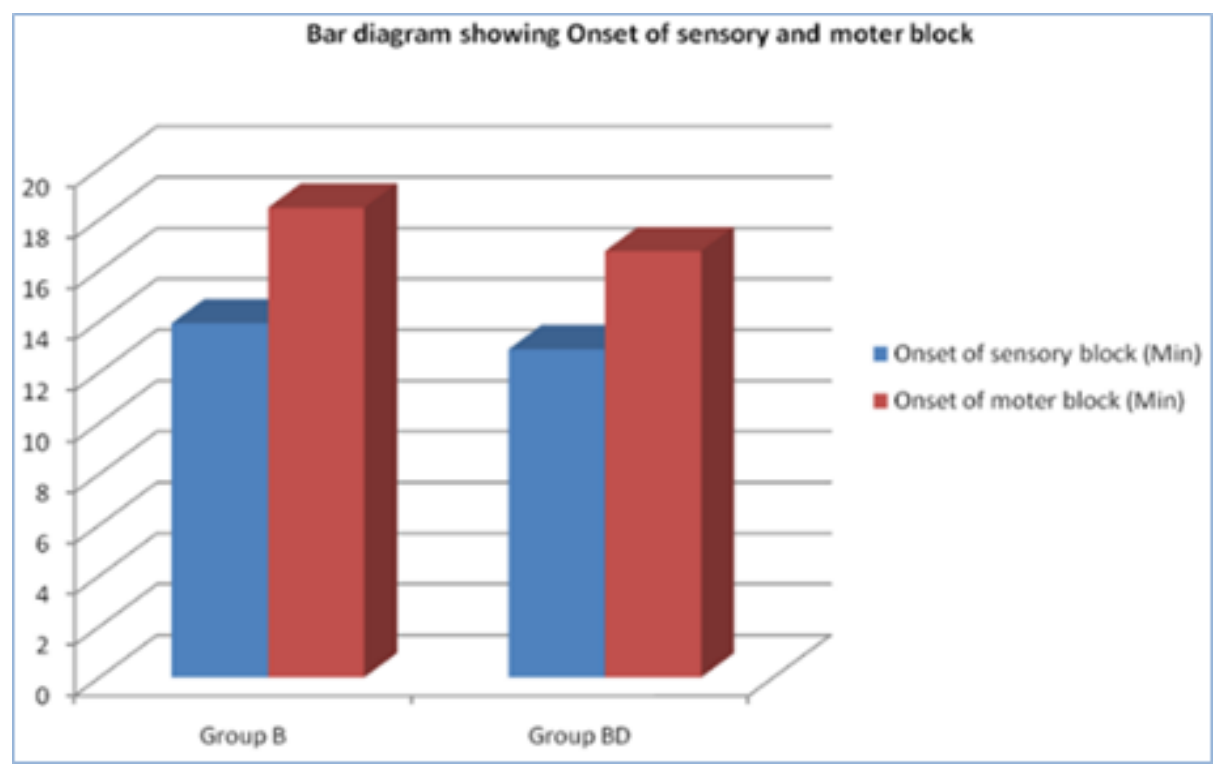

Figure 1

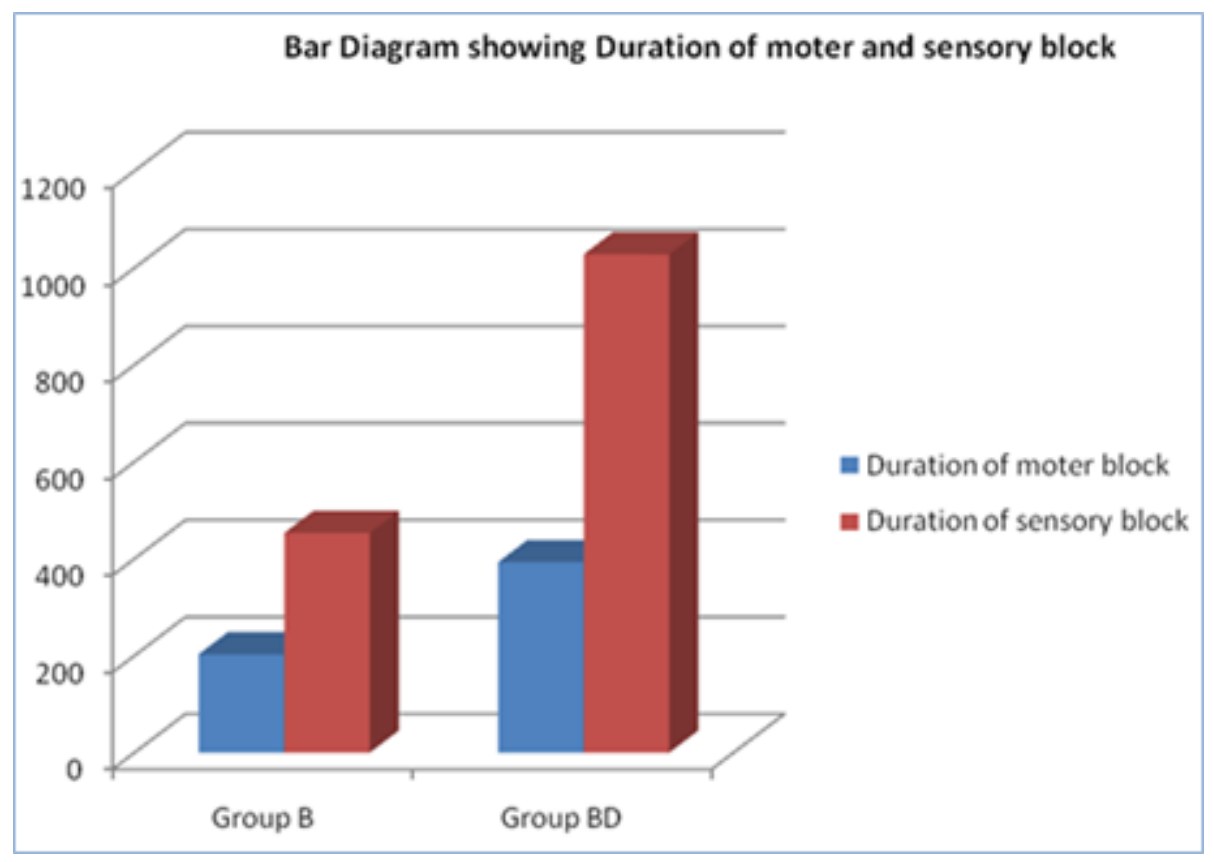

Figure 2 


\section{ORIGINAL ARTICLE}

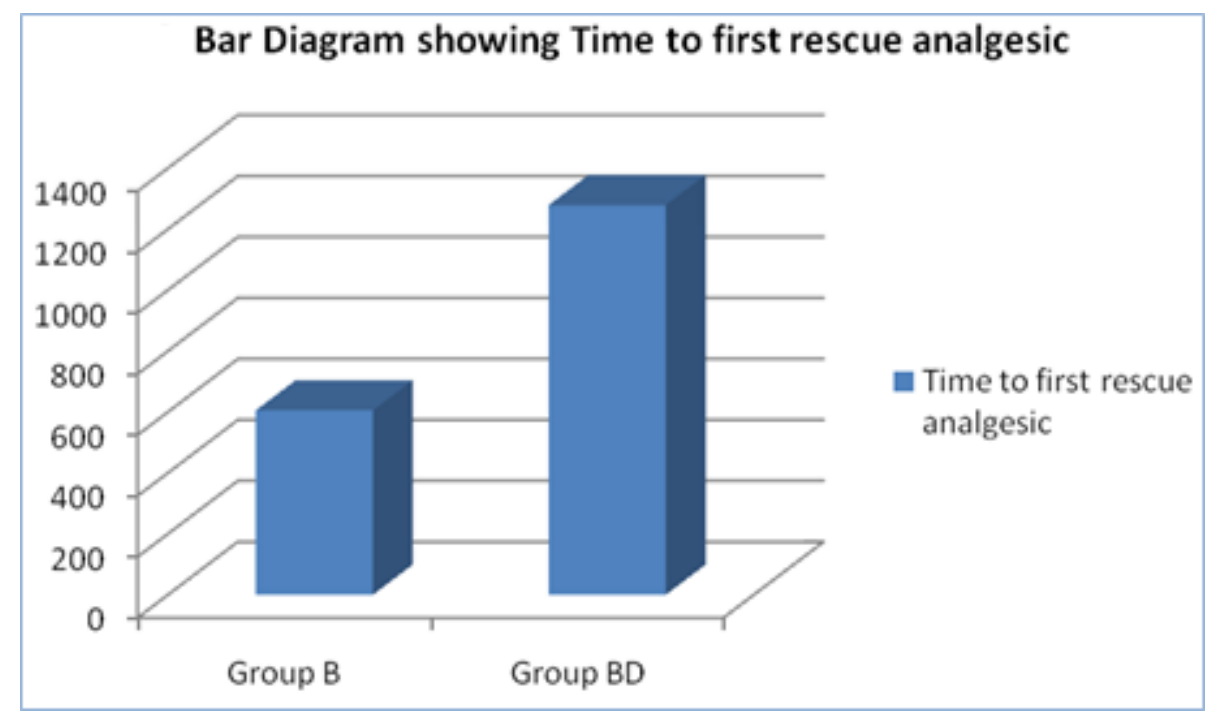

\section{Figure 3}

\section{REFERENCES:}

1. McCartney CJ, Brull R, Chan VW, Katz J, Abbas S, Graham B, et al. Early but no long-term benefit of regional compared with general anesthesia for ambulatory hand surgery. Anesthesiology. 2004; 101: 461-7.

2. Damien B, Murhy, Colin JL, Carteny, Vincent WS. Novel analgesic adjuvants for brachial plexus block: A systemic review. Anesth Analg, 2000; 90: 1122-8.

3. Duma A, Urbanek B, Sitzwohl C, Zimpfer M, Kapral S. Clonidine as an adjuvant to local anaesthetic axillary brachial plexus block: A randomized, controlled study. Br J Anaesth. 2005; 94: 112-6.

4. Karakaya D, Buyukgoz F, Baris S, Guldogus F, Tur A. Addition of fentanyl to bupivacaine prolongs anesthesia and analgesia in axillary brachial plexus block. Reg Anesth Pain Med. 2001; 26: 434-8.

5. Golwala MP, Swadia VN, Dhimar AA, Sridhar NV. Pain relief by dexamethasone as an adjuvant to local anaesthetics in supraclavicular brachial plexus block. J Anaesthesiol Clin Pharmacol. 2009; 25: 285-8.

6. Cummings KC, 3rd, Napierkowski DE, Parra-Sanchez I, Kurz A, Dalton JE, Brems JJ, et al. Effect of dexamethasone on the duration of interscalene nerve blocks with ropivacaine or bupivacaine. Br J Anaesth. 2011; 107: 446-53.

7. Dar FA, Najar MR, Jan N. Effect of addition of dexamethasone to ropivacaine in Supraclavicular brachial plexus block. Indian J Pain. 2013; 27: 165-9.

8. Biswas S, Das RK, Mukherjee G, Ghose T. Dexmedetomidine an adjuvant to levobupivacaine in supraclavicular brachial plexus block: a randomized double blind prospective study. Ethiop J Health Sci. 2014; 24(3): 203-8.

9. Vishnu Vardhan A, Vishnu Mahesh Babu B, Sai Naveena Lakshmi B. Effect of Dexamethasone with Bupivacaine on Duration of Supra Clavicular Block Compared to Bupivacaine with Normal Saline: A Prospective, Randomized and Double Blind Study. Journal of Evolution of Medical and Dental Sciences 2014; 28: 7861-7869. 


\section{ORIGINAL ARTICLE}

10. Movafegh A, Razazian M, Hajimaohamadi F, Meysamie A. Dexamethasone added to lidocaine prolongs axillary brachial plexus blockade Anesth Analg. 2006; 102(1): 263-7.

11. Biradar PA, Kaimar P, Gopalakrishna K. Effect of dexamethasone added to lidocaine in supraclavicular brachial plexus block: A prospective, randomised, double-blind study. Indian Journal of Anaesthesia. 2013; 57(2): 180-184.

12. Kumar S, Palaria U, Sinha AK, Punera DC, Pandey V. Comparative evaluation of ropivacaine and ropivacaine with dexamethasone in supraclavicular brachial plexus block for postoperative analgesia. Anesth Essays Res. 2014; 8(2): 202-8.

13. Shaikh MR, Majumdar S, Das A, Saha TK, Bandyopadhyay SN, Mukherjee D ei al. Role of Dexamethasone In Supraclavicular Brachial Plexus Block.IOSR-JDMS. 2013; 12: 1-7.

14. Persec J, Persec Z, Kopljar M, Zupcic M, Sakic L, Zrinjscak IK, Marinic DK. Low-dose dexamethasone with levobupivacaine improves analgesia after supraclavicular brachial plexus blockade.Int Orthop. 2014; 38(1): 101-5.

15. Parrington SJ, O'Donnell D, Chan VW, Brown-Shreves D, Subramanyam R, Qu M, Brull R. Dexamethasone added to mepivacaine prolongs the duration of analgesia after supraclavicular brachial plexus blockade.Reg Anesth Pain Med. 2010; 35(5): 422-6.

\section{AUTHORS: \\ 1. Rakesh Nigam \\ 2. M. Murthy \\ 3. D. Kosam \\ 4. A. R. Kujur}

\section{PARTICULARS OF CONTRIBUTORS:}

1. Associate Professor, Department of Anaesthesiology, Chhattisgarh Institute of Medical Science, Bilaspur.

2. Associate Professor, Department of Anaesthesiology, Chhattisgarh Institute of Medical Science, Bilaspur.

FINANCIAL OR OTHER

COMPETING INTERESTS: None
3. Assistant Professor, Department of Anaesthesiology, Chhattisgarh Institute of Medical Science, Bilaspur.

4. Senior Resident, Department of Anaesthesiology, Chhattisgarh Institute of Medical Science, Bilaspur.

\section{NAME ADDRESS EMAIL ID OF THE CORRESPONDING AUTHOR:}

Dr. Rakesh Nigam,

House No: 23, Om Garden, Nehru Nagar, Parijat Colony, Bilaspur, Chhattisgarh.

E-mail: bangonigam@gmail.com

Date of Submission: 21/07/2015.

Date of Peer Review: 22/07/2015.

Date of Acceptance: 04/08/2015.

Date of Publishing: 07/08/2015. 